\title{
Erratum to: Morphometric distinction between bilobate phytoliths from Panicum miliaceum and Setaria italica leaves
}

\author{
Welmoed A. Out ${ }^{1} \cdot$ Marco Madella $^{2}$
}

Received: 6 July 2015 / Accepted: 7 July 2015 / Published online: 25 July 2015

(C) Springer-Verlag Berlin Heidelberg 2015

Erratum to: Archaeol Anthropol Sci

DOI 10.1007/s12520-015-0235-6

The discriminant function in the original version of this article has an error that is hereby being corrected. The change does not affect the results presented in the paper, but allows for the successful application of the discriminant function in future research.

The new discriminant function, based on the unstandardized canonical discrimination function coefficients, is $\mathrm{DF}=-46.628+$ 4.079*Aspect Ratio $+32.887 *$ Circularity $+10.667 *$ Roundness

$+17.560 *$ Solidity $+0.420 *$ Shape $-6.378 *$ Rectangularity

$-14.490 *$ ModRatio. The variables included in the function remain the same.

The online version of the original article can be found at http://dx.doi.org/ 10.1007/s12520-015-0235-6.

Welmoed A. Out

w.a.out@ufg.uni-kiel.de

1 Graduate School 'Human Development in Landscapes'/Institute of Pre- and Protohistoric Archaeology, Kiel University, Johanna-Mestorf-Strasse 2-6, 24118 Kiel, Germany

2 CaSEs Research Group, ICREA - Department of Humanities, University Pompeu Fabra and IMF-CSIC, C/Trias Fargas 25-27, 08005 Barcelona, Spain 